\title{
Developing Supported Health Tourism Cluster for High Quality Tourism of BRIC in Active Beach Group of Thailand
}

\author{
Nattada Srimuk ${ }^{1}$, Therdchai Choibamroong ${ }^{2}$
}

\begin{abstract}
:
This study focuses on promoting high quality tourism from BRIC, specifically. The Thailand Tourism Department plans to support the development of this market. The eastern Thai provinces, have great tourism potential--Thailand Tourism Cluster (TCC), Active Beach. These provinces offer numerous, varied and unique activities to the tourist. The Thai Government has the budget for development, growth and improvement of tourism to high revenue potential for the health tourism industry and local community economies, in general. All parties received opportunity for all involvement in the process of drafting the strategic plan that would be recognized and applied in practice. The plan, as developed, recognizes that Thailand is an attractive target for high quality tourism. Health tourism development may have many beneficial consequences, both economic and environmental, for a destination. Research driven cluster is a development of a model to promote health-oriented, participatory and sustainable to cater to the provinces in the active beach.
\end{abstract}

Key Words: Supported Health Tourism, Cluster Development, High Quality Tourism, Spa and Massage Health, Active Beach

JEL Classification: M20, I15

\footnotetext{
${ }^{1} 295$ Business Administration Program Faculty of Management Science, Suan Dusit Rajabhat University,Thailand nattada.sri@gmail.com

${ }^{2}$ Acting Dean of Graduate School of Tourism Management National Institute of Development Administration (NIDA), Thailandtedchoibamroong@ hotmail.com
} 


\section{Introduction}

Supported health tourism is relatively resent term, but it is not a new phenomenon. People have been travelling to seek better healthcare for many year. The main purpose of a health tourism promotion visit is to provide physical and mental health care facilities for medical related treatment, and rehabilitation. Additionally, this model provides the opportunity to share experiences and social promotion of good health with others during the tour, causing changes in behaviour, attitudes and values to promote and maintain health and self-improvement. Health promotion, selfexpression can come in the form of exercise and sport, weight control, appropriate food and drinks, along with healthy herbs. To calm the mind, Buddhist religious meditation practice, will be taught and demonstrated. The use of herbal medicines with fewer side effects, than western drugs, will be available. (Ministry of Public Health, 2011,p. 14).

Thailand was the first country to set an explicit standard of service health spas. The Ministry of Health has set the definitions. What about the health and beauty services Act 1966 (Amendment, 2004) A health spa business provides health care services and primary health services including massage, water and health-supplements, exercise, nutrition and diet therapy, Yoga and meditation, the use of herbs, medical and/or other health products, as well as other alternative medical practices. The Thailand government encourages foreign patients to receive medical treatment in Thailand, which is another Thai income source. And, in accordance with the complete Thai concept, "Health services in a centre". Further, the Thai Government developed plans to make Thai a 'Medical Hub' for Asia to promote the medical tourism, especially for Japanese and Chinese citizens, which is Dental care spa and massage, Thailand. (Ministry of Public Health, 2011, p14). The market for health spa and massage in Thailand is constantly evolving into higher growth potential along with a rapid growth in the business districts and tourist attractions. Tourism is one of a group of Thai businesses that have high potential to extract revenue from foreign visitors (more than 24,000 million tourists in 2012).

The World Tourism Organization(WTO, 2006) forecasts appear headed for a large tourism increase by 2020-an increased number by the year 1995 - from 565 million to 1,561 million in 2020, of which Europe is the number one tourist area for Thai--as much as 45 percent. Foreign tourists' arrivals to Thailand reached 15.93 million, up from last year. (TAT, 2010) European tourists are 12.63 percentages of approximately 4.4 million people in the south of Russia 6.4 million. I have increased the percentage of 92.24 by January - August 2554, there is the Russia travel to Thailand, 6.1 million people are expected to end the year 2012 to review the Russians came to 8.4 million, which is rated \# 1 in the Europe tourist arrivals in Thailand . Russia is a member of a group of countries in the Russian Federation. The 
economic expansion is rapid. It is due to the developing economic powers, such as Brazil, Russia, India and China (BRIC). (Ministry of Tourism and Sports, 2011). Indian tourists had high purchasing power. Their number increases in Thai tourism market approximately $11 \%$ per year. Brazil is far from Thailand. This fact keeps the number of Brazilian tourists in Thailand relatively low, accounting for 0.42 percent of Brazilian international tourists $(6,000,000$ per year). So the study did not include these Brazilians. Most Chinese, Russian and Indian tourists belong to medium to low income groups. This prompted the Tourism Authority of Thailand (TAT) to steer off their marketing strategies from concentrating on the sheer number of tourists to high quality tourism and niche market tourism aimed mainly at medium to high income tourist's high quality tourism and niche market tourism.

In the Thai government promotional, 'set-up' tour for tourists traveling from Russia. The Tourism Authority of Thailand (TAT) will organize yearly meetings between corporate Thailand and Russian travel companies. Especially in MATIW--Leisure 2012 exhibition in Moscow, Russia, to promote tourism to Russian people, who find spa services very attractive--the spa and Thai massage, and to demonstrate and invite Russian tourists' spa and Thai massage services. The Russian tourists are expected to continue to travel to Thailand--not less than one million people will travel to the cities. The Pattaya city in Chonburi province is a potential tourist town in the eastern seaboard--the Active Beach group cluster.

The present study answers these calls by objective of this research, developing a strategic cluster of supported health tourism for tourist of BRIC in Active Beach Group of Thailand. The strategies must be a pattern for participation of member partners and increase the numbers of participation methods for growing the tourism market and related businesses, specifically. To educate, to influence tourism behaviour, through encouraging business competitiveness and cooperation within the cluster, educate the Government Department of Tourism to its interactive role, and the roles of local governments and rural communities. To developing strategic cluster of supported health tourism for tourist of BRIC in the Active Beach group of Thailand. Finally, based on the above, I offer implications for theory, practice, and future research

\section{Active Beach Travel Group Interactive}

The East coast provinces--Chonburi, Rayong, Chantaburi and Trat--compromise one of the eight greatest potential tourism areas of Thailand (Thailand Tourism Cluster TTC) (National Tourism Development Plan, from 2012 to 2016) for tourist visits and general tourist attraction. 


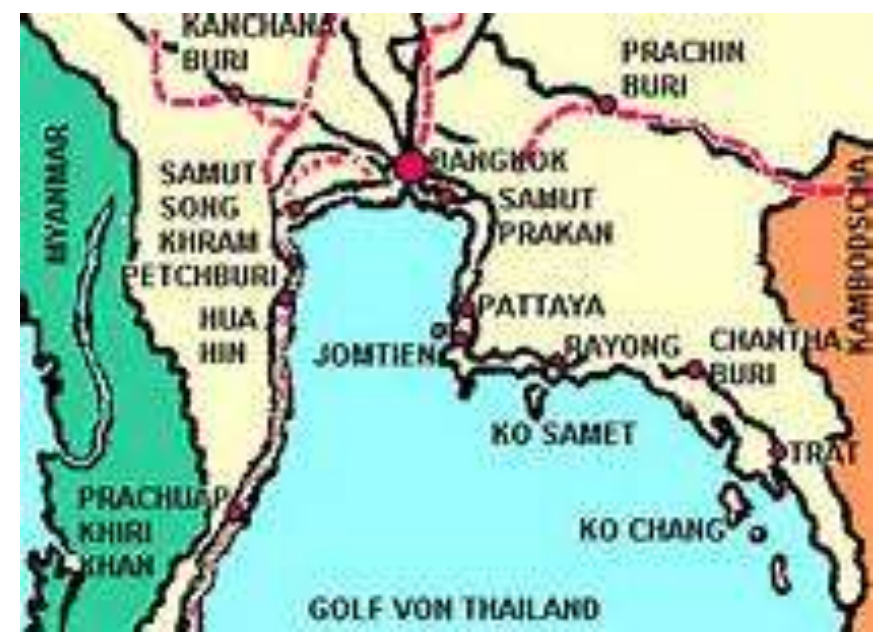

Figure 1. The East coast provinces of Thailand

The potential tourism markets, and massage health spa in Thailand is constantly evolving. A rapid growth is anticipated in the business district and tourist attractions. Tourism is one of a group of businesses/industries that has high growth potential. To extract revenue from foreign visitors--more than 24,000 million in 2012, the Russian tourists are calculated to travel to Thailand, with not less than one million people travelling to the cities. The city of Pattaya is a potential tourist town in the eastern province are Active Beach

Number of tourists visited by the tourists and sightseeing. By the Department of Tourism, 2009-2010, Trend tourists Pattaya are -4.53 percent increases in the maximum number of tourists. Increased by 78.1 percent from the average of both Thailand and foreign tourists. 2-3 days at foreign tourists to stay longer than tourists in Thailand in Chonburi, Rayong and Trat. The averages stay at Chantaburi province in Thailand for more than a few foreigners. Nationality of the travellers using accommodations--Hotel Guesthouse \& Resort--in Chanthaburi and Rayong in Thailand are more than 90 percent Tread tourists in Thailand 65 percent as the German 5 percent of the Swedish 4 percent Chonburi tourists in Thailand. Only 35 percent are Russians and the Chinese 20 percent to 10 percent.

The market for health spa and massage in Thailand is constantly evolving into higher growth potential along with a rapid growth in the business districts and tourist attractions. Tourism is one of a group of Thai businesses that have high potential to extract revenue from foreign visitors (more than 24,000 million tourists in 2012). The word "spa", in accordance with the principles of international organizations, International Spa Association (ISPA - Europe) includes: 1) Hotel \& resort spa. 2) A destination spa. 3) A medical spa. 4) Day Spa or City Spa. 5) Mineral Spring Spa. 6) 
Club Spa. 7) Cruise Ships Spas. Entrepreneurs in the tourism industry, provide products for health and beauty. The form of the three types of spa business: 1) Health Spa Business. 2) Massage for Health related Businesses.3) Massage for Herbal Business. Survey of research on the behaviour and preferences of foreign countries, health and beauty (Spa and Wellness) is divided into two types of establishment groups (Tourism Authority of Thailand, 2011).

World Trade Organization (WTO) have been documented, MTN. GNS/W/120. It divides into 12 service areas in which the services are classified based on the Central Product Classification (CPC) of the United Nations. Thailand's FTA negotiations and the WTO services classification the other services. Related to health, such as spa, massage, Thailand etc. Service spa. Present in the establishment of quality criteria for health spa. This standard consists of the following (Thailand Spa Association, 2012). In purpose, to check the service's activities are complete, accurate service..

Standard 2: The Staff (Skill Staff). Objective To evaluate the ability of personnel in the health spa that has features to customer service, safety and hospitality problem or emergency. Kotler (1994: 464-468) states that the service is defined as any general service, activity or action that one party can offer to another. Which are not tangible and cannot result in the ownership of any of the actions that may be included or not included with the product existed. Early pioneering research that led to the creation of the TALC model was conducted in the early to 1900's and is well summarized in the classic book, Diffusion of Innovations (Rogers, 1962). Another work on the traditional model is "A Propositional Inventory for New Diffusion Research", by Gatignon and Robertson (1985).The model has gained widespread acceptance and is presented in several college marketing textbooks, often without reference to the early researchers. Recent modifications to TALC were published in popular books written by Geoffrey A. Moore. In Crossing the Chasm (Moore, 1999), Moore discussed the existence of gaps between the five adopter categories, especially a significant chasm between early adopters and the early majority. While the TALC suggested smooth transitions between categories, Moore's work proposed that a firm's failure to recognize transitions and to adjust their marketing strategies accordingly, could lead to the early failure of a product. In Inside the Tornado (Moore, 1995), Moore discusses three stages that occur after crossing The Chasm to the early mainstream market. These stages are The Bowling Alley, The Tornado, and Mainstream. Successful marketing of an innovation in the early mainstream market depended on recognition of these stages and adopting an appropriate strategy for each. 


\section{Sustainable Tourism Cluster of Active Beach in Thailand}

According to Thailand's Competitiveness: Creating the Foundations for Higher Productivity (Michael E. Porter, 2003), there are many 'well-functioning' tourism clusters in Thailand. These clusters however lacked clear strategies and clear strategic plans which limited their increase in competitiveness, i.e. in capturing more tourists. Cluster policy needs to be an important tool for achieving environmental sustainability (Christian,H.M. and Ketels, 2009). This can be done by pursuing environmental issues that exist within each cluster and encouraging new clusters to develop that target emerging environmental markets and relating these two different areas of Thai strengths. Cluster policy needs to be an important tool for achieving environmental sustainability environmental sustainability.

In recent years, the tourism sector of Thailand various factors influenced the industry, such as: the global economic crisis, political unrest and the spread of some diseases. The Government recognizes the importance of the tourism sector of the Thai economy the Active Beach Group Cluster, TTC (Thailand Tourism Cluster), --a potential tourism growth clusters of Thailand (Thailand Tourism Cluster - TTC), one of eight groups / areas to visit a tourist attractions and build further potential. It is critical that Thai tourism groups to create value and value-added.

The 2012-2016 national plan aims to develop products and services with the following guidelines (Ministry of Tourism and Sports, 2012):

1) Develop standards for uses a framework for improving the quality of the tourism establishments and recognized international standards.

2) Promote and encourage the establishment of a standard travel services in all sectors to improve the service and the establishment of their own professional standards.

3) Support the assessment and certification of tourism enterprises, according to international guidelines.

4) Promote activities to attract tour operators and travel into the minor Thailand provinces/tourism destinations., including a push Thailand to develop a certified travel to build the trust and confidence in Thailand and foreign countries.

5) Prepare a database for tourist attractions with links to the full service, meeting the needs of users, by collecting real useable data. 
A strategic tourism plan developed--spanning both the public and private sectors of the tourism industry and taking into account the environmental factors associated with the activation and recovery of the tourism sector. All parties received opportunity for all involvement in the process of drafting the strategic plan that would be recognized and applied in practice. The plan, as developed, recognizes that Thailand is an attractive target for high quality tourism. Organized tourist destinations cannot be in a state of decline or deterioration and must be in as pollution free environment as possible. Tourist activities also require good hosts.

Tourism Authority of Thailand (TAT) is the policy of the Board of Directors from 2007 to 2011 to promote the country's sustainable growth, focusing on expanding markets and quality, both in the Active Beach, niche markets and in the promotion of tourism as a part of Thai life. Emphasis on coordination between the government and the private sector is a critical component of the Cluster Concept. Stimulating domestic tourism that contributes to learning creates benefit for both the family and the society as a whole. All of the above will lead to the creation of environmental awareness, as well as the love and pride in the unique culture of Thailand. Further, the strategic tourism plan will increase the competitiveness of the region in the world tourism market.(Business Travel Association of Thailand, 2011).

Different regions experienced dynamism and robustness when different clusters have dialogue and positive relationship not only among themselves, but also with government or the clusters' support institution (i.e universities). These are the regions that saw faster growing economies, higher job, and wage and wealth creation than regions where clusters are not well integrated.

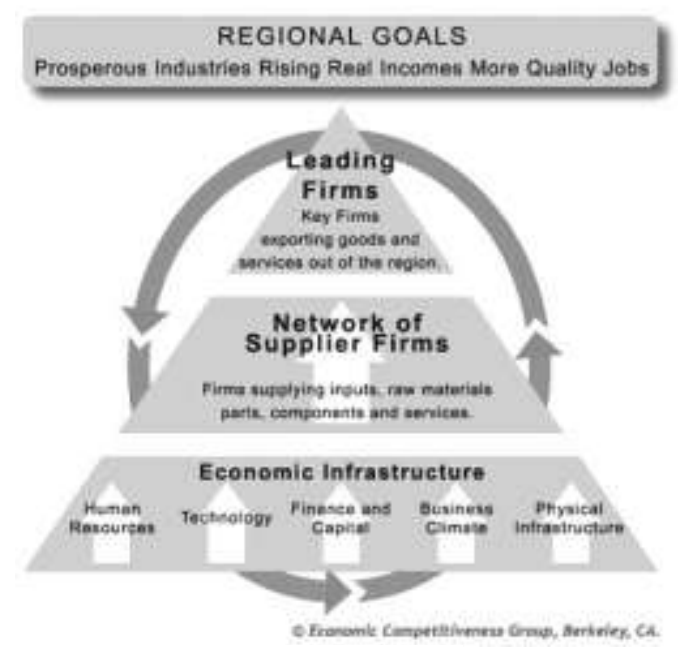

Figure 1. Cluster-driven development process

Source: Association of Latvian Travel Agents and Operators, 2012 
Strategies for a Cluster-driven development model to promote a healthy and sustainable participation of the BRIC tourists in provinces catering to the active beach. Under the development budget to promote Thailand tourism, 7000-8000 million, or more, is allocated to jointly integrate all sectors, with the implementation of the National Tourism Development Plan, in line with the recovery plan for the cities to their full potential. Characterized by the tourist areas of Thailand and create income for local people and to be sustainable. The aim is to provide an effective, fast and efficient plan. The Thai Government has set an action plan in line with the Tourism development plan 2012-2016 and the national action plan to appoint a subcommittee under the National Tourism development plan. The Government approved a fund of 6.65 billion baht to develop eight clusters for tourism development in the next three years. The fund will be spent on 385 projects from 2012 to 2014, when major tourism sites across Thailand will be rehabilitated and upgraded on a sustainable basis. Active beach, it involves 44 projects worth 770 million baht.

Five Forces model, in which market factors can be analyzed so as to make a strategic assessment of the competitive position of a given supplier in a given market.(Porter, M., 1990) The five forces that Porter suggests drive competition are existing competitive rivalry between supplier ,threat of new market entrants bargaining power of buyers, power of suppliers, threat of substitute products (including technology change). And Porter is also particularly recognized for his competitive 'diamond' model, used for assessing relative competitive strength of nations, and by implication their industries (Porter, M., 1990)

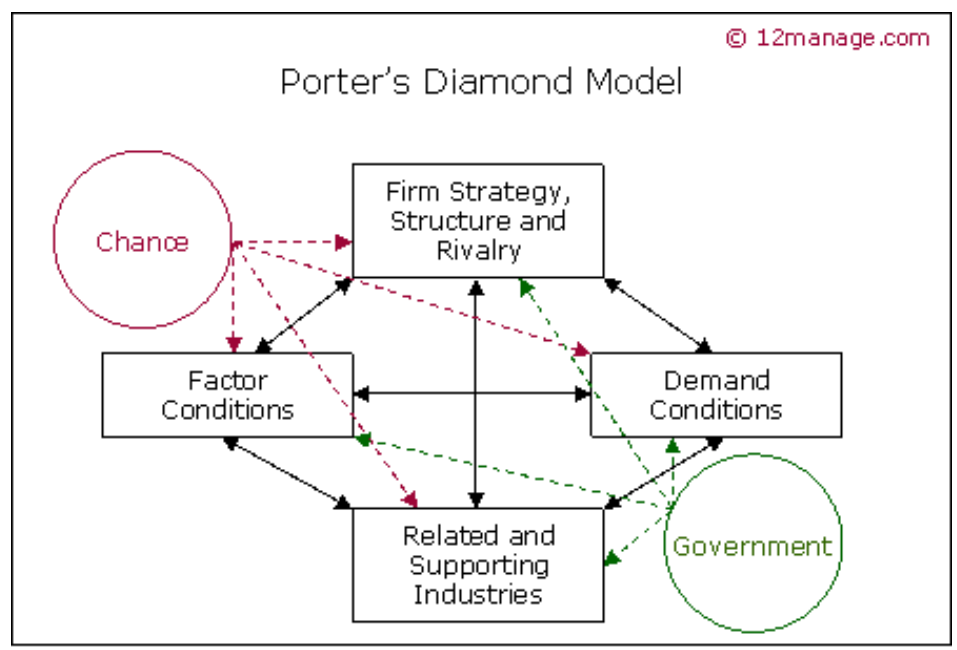

Figure1. Competitive diamond model

Source: Michael E. Porter, 1990 
These six attributes promote or impede the creation of competitive advantages of firms, clusters, and nations. All conditions need to be present and favorable for an industry/company within a country to attain global supremacy. The cluster is aimed at creating collaboration between different fields of knowledge, practice and expertise among travel agents/operator, tourism service provider and research and educational institutions. Such collaboration promotes sustainable tourism and company competitiveness including innovating and exportable tourism product formation that provides optimum added value to clients and end consumer of sustainable tourism.

Cluster members include travel agents and tour operators. They are responsible for incoming and outgoing tourists and thus work on the technological capacity of Latvia that facilitate tourists flow and coordination. According to Gitendorfa.K, ALTA chairman of the Board, cluster program allows companies that are normally rivals to come together and discuss ways to cooperate, co-invest and expand into new markets and eventually obtain mutual benefits. Apart from this, this cluster program provides a stage for longer term cooperation. The variables should be taken into driven cluster development model as well.

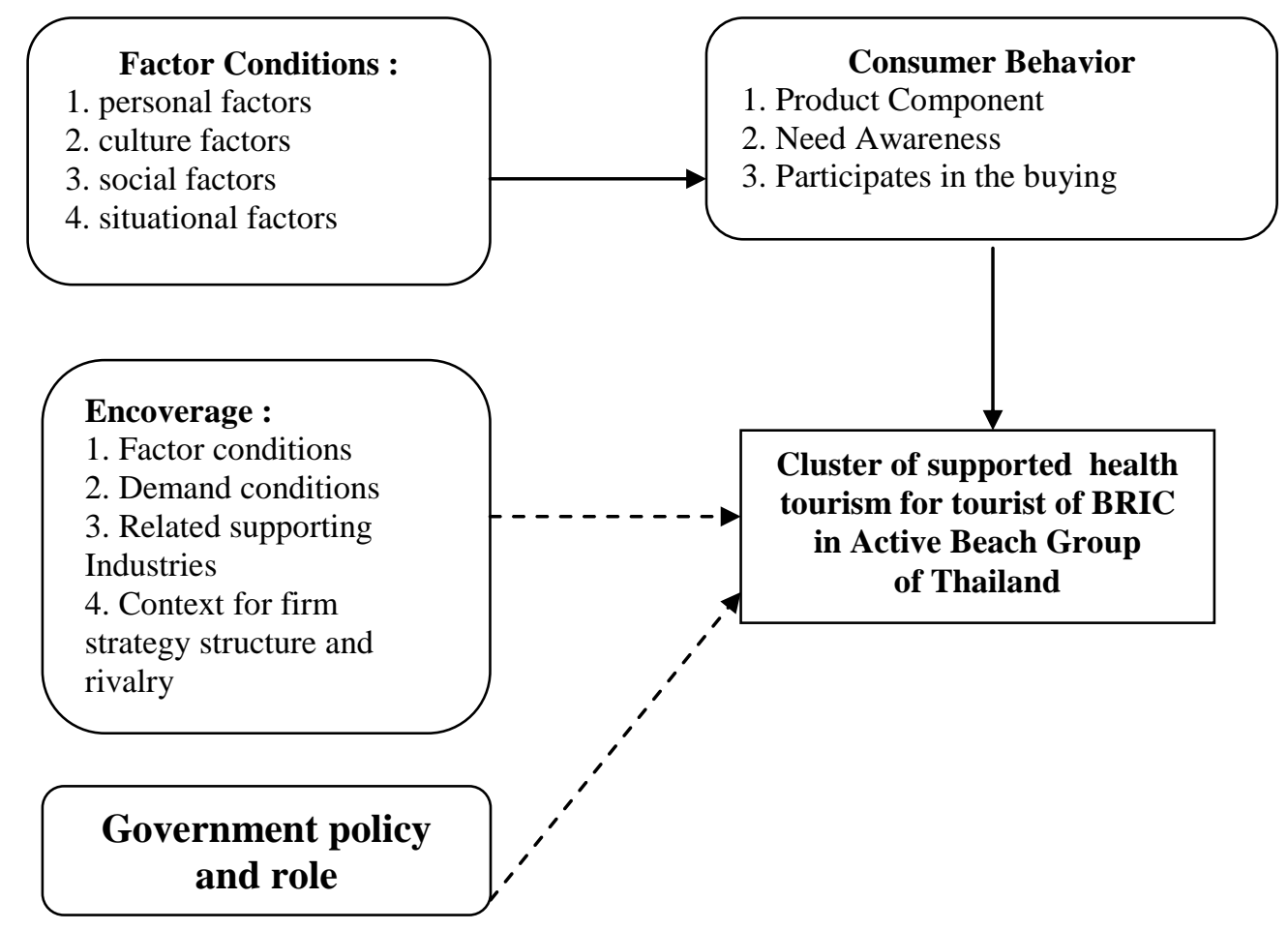

Figure 3. Summarized Variables Used in driven cluster development model 
Research driven cluster development model aims to promote health-oriented, participatory and sustainable to cater to the provinces in the active beach. The details are as follows. A quantitative research study aims to describe the behavior. The research was qualitative research study aimed to investigate the capabilities of the two. And integration of services and business-oriented health promotion related to a mechanism to support the promotion of sustainable tourism development. The third objective was to study the role of government. Local authorities and local communities in the tourism cluster to the promotion of sustainable tourism development. The fourth objective is to find a model driven development to cluster analysis, participatory and sustainable health promotion for BRIC in province interactive beach.

\section{Conclusion}

This study explored theory, Five Forces model, in which market factors can be analyzed so as to make a strategic assessment of the competitive position of a given supplier in a given market and competitive 'diamond' model, used for assessing relative competitive strength of nations, and by implication their industries. Based on a review of guidebooks, interviews with spa owners and inspections of the services and facilities of various types of spa segments, the article concludes that health tourism development may have many beneficial consequences, both economic and environmental for a destination. Information economy, in this study will explore the 'cluster driven concept'--the critical theory, and research related to its support. In other words, the goal here is to guide the education and find model to drive the cluster oriented, participatory and sustainable health promotion for travelers from BRIC in the interactive beach group of Thailand. In the future, this study will potentially provide a model for spa industry growth, increased Thai revenue, community improvement and benefit the entire Thai culture. A Model of developing a strategic cluster of supported health tourism for tourist of BRIC in Active Beach Group of Thailand will provide an essential research proposal and subsequent research for achieving the tangible results. In the future, when results of the research are available for the local communities, connected through participation with the businesses to support health tourism and encourage business competitiveness and cooperation within the cluster. Several Government Departments, for example the Ministry of Tourism and Thailand Authority Tourism can bring results from research to advantage and spa business and massage health development for support health of Russian tourism, developing strategic cluster of sustainability participation of supported health tourism for tourist of BRIC in the active beach group of Thailand. 


\section{References}

Sanatullah A.D. (2011), “After Sales Service and Consumer Buying Behavior: An Empirical Investigation in Automobile Industry of Pakistan", IQRA University Gulshan Campus, Karachi, Pakistan

Association of Latvian Travel Agents and Operators (2012), "Sustainable Tourism Cluster of Latvia on 12 September Entered Into Agreement Nr.LKAP-12-0003", http://tourismcluster.lv/en

Ceglie,G. and Dini,M. (1999), "SME Cluster and Network Development in Developing Countries: The Experience of UNIDO", International Conference on Building a Modern and Effective Development Service Industry from Small Enterprises, UNIDO

Choibamroong,T. (1997), “Knowledge of Tourists' Behaviour: A Key Success Factor for Managers in Tourism Business", Bangkok.

Chirani,M. and Shaabani,A. (2011), "Health Tourism, Tourist Satisfaction and Motivation"

Christian .H. M. and Ketels B. (2009), "Thailand's Competitiveness: Meeting the Challenges of Globalization and Environmental Sustainability", Institute for Strategy and Competitiveness, Harvard Business School, Asia Competitiveness Institute,USA.Gulshan Campus, Karachi, Pakistan.

Darrel,D., Muehling C. and Pascal,V. (2011), "An Empirical Investment of the Differential Effects of Personal, History and non-nostalgic Advertising on Consumer Responses", Journal of Advertising, vol. 40, no. 2 (Summer 2011), pp. 107-122.

Department of Trade Negotiations (2011), "Services: Assuage Thailand", Ministry of Commerce Nonthaburi. Development services to business criteria.

Dodoo.J. (2007), “Practical approach towards consumer's Behavior”, Atlantic International University Hawaii, USA.

Fairbanks,M. and Lindsay,S. (1997), "Plowing the Sea: Nurturing the Hidden Sources of Growth in the Developing World", Harvard Business School Press

Fujita, A. (2005), "A Study on Foreign Tourists' Behaviour and Consumer Satisfaction in KAMAKURA", Journal of the Eastern Asia Society for Transportation Studies, 6, 2154 $-2169$.

Gregorio,F and Sung,F. (2008), "Understanding Attitudes Toward and Behaviours in Resource to Product Placement", USA.

Harrell, G,D. (2002), "Marketing: Connecting with Consumers", New Jersey: Prentice Hall.

Hatch.C,H, (2002), "Towards a strategy for SME Cluster and network development in Thailand", A Discussion Paper for Stakeholders for the international labor Office's Initiative on Business-to-Business Networking, Thailand.

Humphrey,J. and Schmitz ,H. (1995), "Principles for Promoting Clusters \& Networks of SMEs", UNIDO: Small and Medium Enterprises Branch.

Institution for Management Education for Thailand Foundation. (2002), "Competitive Study - Cluster Approach", USA.

Kotler,P. (2009), "Marketing Management", Person Prentice Hall

Kotler,P and Keller.K.L. (2006), "Marketing Management (12 ${ }^{\text {th }}$ ed.)”, Upper Saddle River, NJ: Prentice-Hall.

Ladkin ,A. and Weber,K. (2009), "Tourism and Hospitality Academics: Career Profiles and Strategies", Journal of Teaching in Travel \& Tourism, 8:4, 373-393.

Mayar .R. N. (2006), "Measuring What Really Matters to Consumers", The Journal of Consumer Affairs. 
Miller,R. K., Washington D., and Kelli P. (2008). "Travel and Tourism Market Research" Handbook. 214-216.

Narayana R., (2011), "Management Theory Review: Consumer Behaviour", http://nraomtr.blogspot.com/2011/12/consumer behavior.html

Nicaretta O.,L, Rossi,G, and Gervasoni,V. (2011), "What are the Attractiveness Factors that Influence the Choice of a Tourist Destination-A Study of Brazilian Tourist Consumer", Chinese Business Review, David publishing,

Oonjitt ,C. and Vasinonta .A. (2002), "Cluster : Tool for Competitiveness", Mould and Die Journal,4, 19-20.

Porter .M,E. (1985), "Competitive Advantage", United State of America, New York.

Pride, W. M. and Ferrell, O.C. (2003). "Marketing: Concepts and Strategies", Boston: HoughtonMifflin, http://www.sundaytimes.lk/110522/BusinessTimes/bt36.html

Simon, F., Miller, C. and Kotler,P. (1985), "Marketing to A New Consumer", http://www.acrwebsite.org/ proceeding.aspx? Id =12144

Salvador,L. and Rubio,R. (2010), "The Role of Identity Salience in the Effects of Corporate Social Responsibility on Consumer Behaviour"

Stanciu O. and Tichindelean M. (2009), "Consumer Behaviour in the Different Sectors of Tourism", Lucian Blagauniversity of Sibiu, Romania.

Stone, M., Bond, A. and Foss, B. (2004), "Consumer Insight", Kogan Page Publishers.

Tourism Authority of Thailand. (2011), "Behaviour and Satisfaction Survey of Foreign Tourists", Group Health Thailand, Bangkok

UNIDO (2001), "Development of Clusters and Networks of SMEs", Private sector Development Branch, Investment promotion and institutional capacity building division. 